\title{
PERCEPÇÃo dos PAIS SOBRE AMIZAde EM CRIANÇAS TÍPICAS E COM TDAH ${ }^{1}$
}

\author{
Soraya da Silva Sena* \\ Luciana Karine de Souza**
}

\section{Resumo}

A literatura científica brasileira tem mostrado cada vez mais estudos sobre o TDAH em crianças, focalizando tanto questóes de saúde como educacionais. A amizade é sabidamente promotora de desenvolvimento, de aprendizagem e de saúde. Também é reconhecido o papel dos pais na vida social de suas crianças. Assim, o TDAH e as relações de amizade, tanto em crianças sem transtornos como em crianças portadoras destes desafios, persistem merecendo investimento da comunidade científica. O presente trabalho comparou a percepção de pais de crianças com TDAH e de pais de crianças sem TDAH sobre as amizades de seus filhos. Também foram comparadas as respostas dos pais com a de seus filhos com a intenção de avaliar o grau de concordância entre as percepçóes de pais e de filhos. Os resultados têm a intenção de motivar novos estudos empíricos que examinem, mais intensa e extensamente, a amizade em crianças com TDAH e o envolvimento dos pais na vida social das crianças. Duas hipóteses-explicativas principais envolveram a interpretação dos resultados: pais alheios às relaçôes sociais dos filhos e crianças com TDAH com um viés positivo acerca de suas amizades. Aliado a isso, ponderou-se sobre uma tendência dos pais de compreender a amizade desde uma visão adultocêntrica.

Palavras-chave: criança; transtorno; amizade.

* Departamento de Psicologia, Universidade Federal de Minas Gerais. Belo Horizonte, Minas Gerais, Brasil. E-mail: senasoraya@yahoo.com.br.

** Departamento de Psicologia, Universidade Federal de Minas Gerais. Belo Horizonte, Minas Gerais, Brasil. E-mail: lucianak@fafich.ufmg.br. 


\begin{abstract}
PARENTS' PERCEPTIONS OF CHILD FRIENDSHIPS ON TYPICAL CHILDREN AND ADHD CHILDREN
\end{abstract}

Scientific literature in Brazil has shown a growing body of studies about children with ADHD, with focus on either health or educational approaches. As broadly known, friendship promotes development, learning, and health. Parents' role are also recognized in the social life of children. Thus ADHD and friendship relations, in children with or without this disorder, keep deserving scientific attention and effort. This paper compared parents of children with and without ADHD about their perceptions on children's friendships. Parents and children's answers were also compared with the intention of evaluating the degree of agreement between parents and their children. Results aim at fostering new empirical studies that examine most intense and extensively friendship in children with ADHD, and also parents involvement on children's social life. Two main explanatory-hypotheses guided the interpretation of the results: parents unaware of children's social relationships, and ADHD children with a positive bias about their friendships. It was also considered a tendency that parents have to understand and perceive friendship from an adult point of view.

Keywords: child; disorder; friendship.

\title{
Resumen
}

LA PERCEPCIÓN DE LOS PADRES Y AMIGOS DE LOS NIÑOS TÍPICOS CON TDAH

La literatura cientifica brasileña ha mostrado cada vez más estudios sobre el TDAH en los niños, centrándose tanto en cuestiones de salud como de educación. La amistad es conocido promotor del desarrollo, del aprendizaje y de salud. También se reconoce el papel de los padres en la vida social de sus hijos. Por lo tanto, el TDAH y las relaciones de amistad, tanto en los niños sin estos trastornos, como en los niños con estos problemas, persisten dignos de atención de la comunidad científica. Este estudio comparó la percepción de los padres de niños con TDAH y de los padres de niños sin TDAH en las amistades de sus hijos. También se compararon las respuestas de los padres con sus hijos con la intención de evaluar el grado de acuerdo entre las percepciones de los padres y de los niños. Los resultados tienen por objeto motivar nuevos estudios empiricos que examinan más intensa y extensamente la amistad en los niños con TDAH y la participación de los padres en la vida social de los niños. Dos principales hipótesis explicativas fueron implicadas en la interpretación de los resultados: padres ajenos a las relaciones sociales de los niños con TDAH y niños con un sesgo positivo sobre sus amistades. Junto a esto, se consideró la tendencia de los padres a entender la amistad desde la visión centrada en los adultos.

Palabras clave: niño; trastorno; amistad.

Psic. Clin., Rio de Janeiro, vol. 25, N.I, P. 53-72, 2013 


\section{Introdução}

No contexto do cuidado e da educação de crianças é esperado que os pais exerçam um conjunto de habilidades para que seu desempenho garanta algum sucesso na direção de um desenvolvimento saudável pleno em seus filhos. Estudos e pesquisas sobre práticas parentais, práticas educativas, cuidados parentais, metas parentais e estilos parentais destacam os comportamentos necessários para um bom cuidado, educação e desenvolvimento dos filhos (Macarini, Martins, Minetto \& Vieira, 2010).

No Brasil está disponível um instrumento para avaliar os estilos parentais - o Inventário de Estilos Parentais (IEP) (Sampaio \& Gomide, 2006). Este instrumento analisa cinco práticas educativas negativas e duas positivas usadas pelos pais no cuidado e educação dos filhos. A prática de monitoria positiva inclui itens sobre "atenção e conhecimento dos pais acerca de onde seu filho se encontra" e "atividades desenvolvidas por ele" (Sampaio \& Gomide, 2006, p.17), bem como demonstraçóes de afeto e carinho. Já a de comportamento moral engendra a transmissão de valores morais pelos pais aos filhos, por exemplo generosidade, honestidade e senso de certo/errado.

Com base nas duas dimensóes positivas avaliadas pelo IEP, poder-se-ia esperar que, mediante as práticas ligadas à monitoria positiva e ao comportamento moral, os pais tratem de abordar o tema da amizade com seus filhos. Isto porque saber onde o filho se encontra e quais suas atividades muito provavelmente envolverá, em se tratando de crianças e de adolescentes, as relaçôes de pares e, portanto, as companhias das crianças. Nessa mesma direção, conversar sobre amizades envolve conversar sobre os valores morais implicados nestes relacionamentos, como a lealdade, a confidência, o companheirismo e o apoio.

No âmbito dos trabalhos e investigaçóes científicas que focalizam elementos fundamentais para o desenvolvimento infantil com saúde em todos os seus domínios (cognitivo, afetivo, comportamental, social), é destacado o papel das relaçóes sociais sobre a trajetória infantil. A literatura abrange estudos que analisam desde o impacto das relaçóes de pares sobre o desenvolvimento sociocognitivo (Piaget, 1964/1973; Selman, 1980, 1981) até a extensão e profundidade das amizades infantis e sua influência sobre a vida da criança (Bukowski, Newcomb $\&$ Hartup, 1996).

Da gama de estudos brasileiros sobre amizade infantil, são raras as investigações sobre a percepção dos pais sobre as amizades de seus filhos. Todavia, do universo de trabalhos sobre crianças com transtornos de desenvolvimento ou com problemas de comportamento, parece haver um maior interesse sobre o conheci- 
mento dos pais acerca da vida social de suas crianças, especialmente porque estas apresentam dificuldades nessa parte de suas vidas.

Num estudo que envolveu pais de crianças com indicação escolar de problemas de comportamento e pais de crianças com indicação escolar de comportamentos socialmente adequados, Bolsoni-Silva e Del Prette (2002) estudaram a percepçáo destes progenitores sobre os comportamentos dos filhos, suas habilidades sociais, as habilidades sociais dos entrevistados e a relação entre pais e filhos. Um dos aspectos analisados pelos autores foram as interaçóes sociais dos filhos. Alguns pais das crianças com problemas de comportamento admitiram observar que seus filhos tinham maior dificuldade de interação com pares da mesma idade, seja porque brigavam facilmente ou porque se isolavam das outras crianças. Quanto às dificuldades de sociabilidade, apenas no grupo dos pais de crianças com problemas apareceu o conteúdo "ficar retraído" como uma característica atribuída aos filhos. Interessantemente, estes mesmos pais apresentaram um menor número de habilidades sociais educativas. $\mathrm{Na}$ avaliaçáo de Bolsoni-Silva e Del Prette (2002), este último dado indica uma associação entre habilidades sociais dos pais e de seus filhos. Assim, a partir desta pesquisa parece importante reconhecer que os pais de crianças com problemas de comportamento devem estar atentos às habilidades sociais de seus filhos, mas também procurar identificar as próprias dificuldades nessa área e em como abordar esta questão na educação das crianças.

Em um estudo sobre a influência da empatia e de práticas parentais sobre os comportamentos pró-sociais de meninos de 4 a 5 anos, Garcia-Serpa, Del Prette e Del Prette (2006) compararam meninos muito empáticos com pouco empáticos. Foram realizadas observaçóes, aplicação de questionários e condução de entrevistas. Um dos resultados obtidos pelos autores indicou que pais com boas práticas parentais têm filhos com melhor repertório de comportamentos pró-sociais. Em estudo semelhante sobre comportamentos socialmente habilidosos dos filhos e consistência na prática parental, Bolsoni-Silva e Marturano (2007) observaram também que o sucesso das intervençóes dos pais sobre o desempenho social dos filhos depende, inicialmente, da habilidade dos pais de identificar os comportamentos socialmente desejáveis e os problemas a serem corrigidos e evitados.

Os estudos recém-descritos indicam que o desempenho dos pais como cuidadores e educadores e nas suas interaçóes sociais parece exercer forte influência sobre comportamentos socialmente desejáveis nos filhos, o que pode prever uma trajetória de interaçóes sociais significativas e o surgimento de relacionamentos interpessoais saudáveis nas suas crianças. A habilidade dos pais em monitorar e identificar comportamentos sociais adequados e inadequados em

Psic. Clin., Rio de Janeiro, vol. 25, N.I, P. 53- 72, 2013 
seus filhos é um primeiro passo para que as práticas parentais educativas possam incluir a atenção às habilidades sociais dos filhos. Acima de tudo, pais de crianças com bom desempenho social estâo atentos ao mundo social de seus filhos, o que inclui suas companhias, isto é, suas amizades. No entanto, não foram localizados estudos disponíveis no Brasil acerca da percepção dos pais sobre as amizades de seus filhos.

Do contingente de transtornos de desenvolvimento na infância e de problemas de comportamento em crianças, a última década tem trazido à tona um grande interesse científico sobre o Transtorno de Déficit de Atenção/Hiperatividade (TDAH). Áreas como a Psiquiatria, a Educação e a Psicologia têm se dedicado ao estudo deste transtorno, não raro com amparo em estudos da genética, farmacogenômica e neurociências. Na Psicologia, um dos desafios tem sido a acurácia na avaliação da criança para um diagnóstico preciso, dados os instrumentos disponíveis para a avaliação do TDAH (Sena \& Souza, 2008).

Como já vem sendo relatado na literatura, as crianças com TDAH apresentam dificuldades de interação com pares (Goldstein \& Goldstein, 2002; Pelham \& Bender, 1982; Sena \& Souza, 2010). São crianças com temperamento forte, por vezes "mandonas", esquecem combinados e tratos com colegas, perdem objetos emprestados e têm dificuldades para cooperar e persistir nas brincadeiras (Barkley, 2002; Goldstein \& Goldstein, 2002; Hoza et al., 2005; Phelan, 2005). Contudo, estudos conduzidos no Brasil com crianças com TDAH na comparação com crianças típicas não têm encontrado esta mesma intensidade de dificuldades sociais descritas na literatura disponível (Sena, 2009). Ainda assim, Albertassi e Garcia (2006) descrevem que os pais de um garoto hiperativo relataram que a amizade que o filho possui é superficial e restrita.

Os pais de crianças com TDAH têm experimentado desafios no cuidado e educação de seus filhos. O trabalho de Bellé, Andreazza, Ruschel e Bosa (2009), por exemplo, evidencia a situação vivida pelas mães de crianças com TDAH. Estas mães vivenciam maior estresse parental na comparação com mães de crianças típicas, recebem menor apoio social percebido e estáo menos satisfeitas com as opiniôes de familiares e amigos sobre sua performance.

Também Kunrath, Wagner e Jou (2006), em um trabalho mais qualitativo, observaram as dificuldades de pais de crianças com TDAH para lidar com o comportamento dos filhos. As autoras perceberam que os progenitores de crianças com TDAH têm conhecimento sobre quais estratégias são mais adequadas para lidar com seus filhos, mas o cansaço advindo da interação com eles lhes tira energia para utilizar estas estratégias. Assim, práticas educativas mais coercitivas thes parecem fornecer melhores resultados, ao menos em curto prazo.

Psic. Clin., Rio de Janeiro, vol. 25, N.I, P. $53-72,2013$ 
Os dados do estudo de Bellé et al. (2009) e de Kunrath et al. (2006) são importantes na medida em que demonstram que a atenção de pais de crianças com TDAH pode estar menos direcionada à vida social dos filhos do que aos cuidados mais prementes que o transtorno exige. Assim, pode-se antecipar que pais de crianças com TDAH saibam menos sobre as amizades dos filhos do que mães de crianças típicas.

Programas de intervenção para crianças com TDAH têm procurado amparar e habilitar famílias, professores e as próprias crianças que convivem com este transtorno. Daly, Creed, Xanthopoulos e Brown (2007) analisaram os procedimentos e resultados obtidos com intervençóes psicossociais para crianças com TDAH. Intervençóes baseadas em evidências têm envolvido pais e os aspectos acadêmicos, de pares e a dinâmica da sala de aula de crianças com o transtorno. $\mathrm{O}$ treinamento para pais abrange, em linhas gerais, habilidades para que sejam dirimidos os reforçamentos positivos aos comportamentos desafiadores e disruptivos das crianças com simultâneo exercício para aumentar o reforço dos pais a comportamentos apropriados de seus filhos. Embora os estudos demonstrem resultados diferenciados muito provavelmente em virtude das diferenças metodológicas entre as intervençóes, tem-se notado efeitos positivos quando as crianças são mais novas e ainda dependentes do cuidado dos pais, mostrando-se mais responsivas a eles.

O escopo de intervençôes dedicadas às relações de pares de crianças com TDAH tem abordado o treinamento destas crianças para habilidades sociais, resolução de problemas sociais e comportamentos socialmente competentes. Esta abordagem pró-social abarca o desenvolvimento de cooperação, comunicação adequada, participação e validação (isto é, reconhecimento de e consideração por outrem). Os programas de promoção de habilidades sociais nas crianças com TDAH têm indicado resultados mais eficazes quando incluem treinamento para pais. Daly et al. (2007) também perceberam o argumento de que as crianças com este transtorno devem ser amparadas para construir e manter amizades próximas. Como exemplo, os autores citam o trabalho de Hoza, Mrug, Pelham Jr., Greiner e Gnagy (2003) que descreve um programa dedicado a promover a amizade em crianças com TDAH. As crianças foram pareadas com outras, sem o transtorno, em atividades específicas, mediante reforçamento, e foi solicitado aos pais que facilitassem encontros das duplas em suas casas. Foram notadas melhoras no desempenho acadêmico das crianças com TDAH, que demonstraram melhor qualidade em suas amizades, bem como foram percebidas como melhor socialmente adaptadas. Os efeitos observados foram mais fortes nas famílias com pais mais comprometidos com o programa.

Psic. Clin., Rio de Janeiro, vol. 25, N.I, P. 53-72, 2013 
Intervençóes com delineamentos que envolvem crianças, pais e professores têm amplitude maior para abordar um transtorno de natureza multifatorial como o TDAH, e, portanto, maior chance de sucesso. A literatura de intervenções baseadas em evidências destaca o envolvimento dos pais no tratamento comportamental das crianças com TDAH. Raros programas, como o de Hoza et al. (2003), incluem relações de amizades. No entanto, nesta ausência, parece importante incluir no trabalho com pais a questâo das relaçôes de pares dos filhos, ajudando-os a identificá-las, acompanhá-las e fomentá-las. Isto é desejável para crianças típicas, mas tem se mostrado de grande relevância no caso de crianças com TDAH.

O presente trabalho comparou a percepção de pais de crianças com TDAH e de pais de crianças sem TDAH sobre as amizades de seus filhos. Também foram comparadas as respostas dos pais com a de seus filhos com a intenção de avaliar o grau de concordância entre as percepçóes de pais e de filhos sobre a amizade destes últimos.

\section{Procedimentos metodológicos}

Esta investigação é parte de um estudo maior conduzido sobre amizade em meninos com TDAH (Sena, 2009). Contudo, os dados coletados com os pais destas crianças são inéditos, e também inéditas são as análises comparativas entre a percepção destes pais e a de seus filhos.

Dois grupos de pais foram organizados para a análise presente: pais de meninos com TDAH (grupo clínico) e pais de meninos sem TDAH (grupo típico). No estudo anterior, foram analisados os dados de 21 meninos sem o transtorno e de 18 meninos diagnosticados com TDAH. Todas as crianças eram do sexo masculino, com idade média de 8 anos e 6 meses no grupo típico, e de 8 anos e 4 meses no grupo clínico. As crianças típicas foram convidadas a colaborar com o estudo, bem como seus pais, através de contato com duas escolas públicas de Belo Horizonte, escolhidas por critério de conveniência. As crianças com o transtorno foram indicadas através de contato com psicólogos e psiquiatras que previamente diagnosticaram os meninos com TDAH. No total, conseguiu-se a participação de 21 pais de meninos típicos e de 18 de meninos com TDAH.

Todos os pais responderam a uma entrevista semiestruturada sobre amizade do filho participante da pesquisa. A entrevista apresentava perguntas semelhantes às realizadas com as crianças, a saber: seu filho tem algum colega

Psic. Clin., Rio de Janeiro, vol. 25, N.I, P. $53-72,2013$ 
com quem gosta de estar?; quem é? (nome; parente, vizinho, colega de sala, etc.); quantos anos tem?; você os considera amigos? (se não, seu filho tem algum amigo?); por que você os considera amigos?; com que frequência seu filho encontra esse amigo?; o que eles costumam fazer quando estão juntos?; há quanto tempo eles são amigos?; seu filho tem outras amizades?. Uma questão foi adicionada para inquirir sobre a atitude dos pais sobre as amizades do filho: como você lida com a(s) amizade(s) de seu filho? A entrevista encerrava dando-se a oportunidade de o entrevistado manifestar-se sobre algo que quisesse.

As entrevistas com os pais de crianças com TDAH foram realizadas em suas residências ou em local apropriado fornecido pela instituição que indicou a família. As entrevistas com os pais dos meninos típicos foram realizadas por telefone em virtude da indisponibilidade dos mesmos em serem entrevistados no ambiente escolar, local onde seus filhos foram contatados e participaram da pesquisa. As entrevistas com todas as crianças foram gravadas e posteriormente transcritas. Porque os pais de crianças típicas foram entrevistados por telefone com entrevistas não-gravadas em áudio (apenas com registro em papel), optou-se pelo mesmo procedimento com os pais de crianças do grupo com TDAH. Todos os pais assinaram um Termo de Consentimento Livre e Esclarecido (TCLE), que foi previamente aprovado, bem como a pesquisa, pelo Comitê de Ética em Pesquisa da Universidade Federal de Minas Gerais. Os pais do grupo típico receberam o TCLE em casa, que autorizaram a participação da criança e também o contato da pesquisadora para realização da entrevista com eles próprios. Os pais de crianças do grupo clínico assinaram o TCLE imediatamente antes do início da entrevista, mediante contato prévio e autorização para tal.

As respostas dos pais foram analisadas com inspiração nos critérios do procedimento conhecido por Análise de Conteúdo conforme proposto por Bardin (2009). Primeiramente as transcriçôes foram lidas para familiarização com os conteúdos. Em seguida, com base nas categorias criadas para a análise das entrevistas com os meninos (Sena, 2009), os dados com os pais foram relidos e, para cada resposta de cada questão, foram identificadas as unidades temáticas que indicavam conteúdos similares àquelas presentes nas categorias construídas com os dados das crianças. A exceção foi com a questão sobre como os pais lidam com as amizades dos filhos. Para estas respostas o procedimento de análise foi a criação de categorias de respostas conforme os conteúdos encontrados. Foram calculadas as frequências de respostas dos pais, por grupo (típico e clínico). Em seguida, estas frequências foram comparadas

Psic. Clin., Rio de Janeiro, vol. 25, N.I, P. 53- 72, 2013 
com as dos filhos. Também foram comparadas as estratégias dos pais sobre como lidar com as amizades de seus filhos, conforme a presença ou ausência de TDAH na criança.

\section{Resultados e discussáo}

A Tabela 1 apresenta as frequências de respostas dos pais do grupo típico (meninos sem TDAH) e dos pais do grupo clínico (meninos com TDAH) no que diz respeito aos seguintes aspectos: se o filho possui algum colega com quem gosta de estar, qual a origem deste colega e por que eles são amigos. A Tabela 2 apresenta como ele (responsável pela criança) lida com as amizades do filho. Não constam na Tabela 2 outras formas de lidar com as amizades do filho (04 ocorrências no grupo típico e 02 no clínico) e outras respostas a esta mesma pergunta (03 e 05 ocorrências, respectivamente).

Tabela 1. Frequência de respostas dos pais sobre as amizades do filho, por grupo

\begin{tabular}{|l|c|c|}
\hline \multicolumn{1}{|c|}{ Aspectos analisados } & $\begin{array}{c}\text { Pais do } \\
\text { grupo típico } \\
\text { filho tem colega com quem gosta de estar }\end{array}$ & $\begin{array}{c}\text { Pais do } \\
\text { grupo clínico } \\
\mathrm{f}\end{array}$ \\
\hline $\mathrm{n}=21)$ & 21 & 15 \\
\hline Origem do colega & & \\
primo & 09 & 02 \\
colega escola & 08 & 04 \\
vizinho & 03 & 08 \\
igreja & - & 01 \\
\hline Justificativa da amizade & & \\
companheirismo ou convivência & 08 & 03 \\
brincar & 07 & 06 \\
comportamentos pró-sociais & 06 & 04 \\
similaridades & 06 & 04 \\
familiaridade ou trocas & 03 & 01 \\
reciprocidade & 02 & 03 \\
atributos amigo & 01 & 03 \\
\hline
\end{tabular}


Tabela 2. Frequência de respostas dos pais sobre como lida com amigos do filho, por grupo

\begin{tabular}{|l|c|c|}
\hline Como lida com as amizades do filho & $\begin{array}{c}\text { Pais do } \\
\text { grupo típico } \\
\mathrm{f}\end{array}$ & $\begin{array}{c}\text { Pais do } \\
\text { grupo clínico } \\
\mathrm{f}=21)\end{array}$ \\
\hline restringe & 10 & 02 \\
incentiva & 05 & 04 \\
busca conhecê-las & 05 & 03 \\
permite & 03 & 04 \\
orienta & 02 & 04 \\
\hline
\end{tabular}

Embora a comparação realizada não permita generalizações nem conclusóes sólidas sobre os dados que apresenta, algumas consideraçóes podem ser realizadas. A primeira delas é a de que três pais, todos do grupo clínico, afirmaram que o filho não possui uma amizade próxima. Um destes pais, identificado pela letra P, justificou sua posição da seguinte forma: "(meu filho) não é de muita convivência, às vezes falo para ele chamar coleguinhas para vir em casa, mas ele não chama. Não se envolve muito... Acho que a culpa é minha, eu devia incentivar mais... Todos os profissionais que consulto me cobram isso". Este resultado vai ao encontro da constatação de Bolsoni-Silva e Del Prette (2002) sobre pais de crianças com problemas de comportamento notarem as dificuldades sociais de seus filhos. No entanto, é digno de nota que este responsável pode estar mais atento porque os profissionais que atendem o filho com TDAH cobram uma intervençáo dele sobre a vida social da criança.

Na percepção do responsável C, "amizade é você procurar o outro, querer estar junto, e isso (meu filho) não faz não... Amigo, amigo de estar junto ele não tem”, enquanto na percepção do responsável B “o $\mathrm{H}$. não é amigo. É só mais ou menos...”. Em contraste, um dos pais do grupo clínico (participante A) que admitiu que o filho possui uma boa amizade encerrou a entrevista com o seguinte comentário: "sinto que não é amizade, acho que é dó". Estes dados parecem semelhantes aos encontrados no estudo qualitativo de Albertassi e Garcia (2006) com um menino com hiperatividade cujos pais qualificaram sua amizade com outro garoto como restrita e superficial.

Embora apenas três pais tenham indicado a ausência de amizade, este dado é condizente com o esperado para crianças com TDAH que são reconhecidas como "mandonas" e desrespeitosas a regras e combinados, comportamentos esses inadequados para as relaçôes interpessoais se estabelecerem e se manterem. O fato de três

Psic. Clin., Rio de Janeiro, vol. 25, N.I, P. 53- 72, 2013 
pais terem assinalado a ausência de amizade do filho parece retratar a visão deles sobre a questão, ou seja, a conceituação de inexistência de amizade do filho seria uma conceituação adultocêntrica dos relacionamentos do filho, uma vez que a mesma está restrita às oportunidades destes pais em abordarem os filhos sobre suas amizades e testemunhar estes relacionamentos. Em outras palavras, é possível que procurem ver nas relaçôes de pares do filho características que ainda estão em desenvolvimento.

É interessante notar a diferença entre a indicaçáo de amizades do filho provenientes da escola e da vizinhança. Os pais do grupo clínico apontaram menos amizades com colegas do que com vizinhos. Nesse sentido, os dados sobre amizade no contexto escolar são condizentes com o esperado para crianças com TDAH, visto que se trata de um contexto onde regras sociais de convivência e de cooperação são esperadas e cobradas destes meninos. Já as relaçóes mais próximas com vizinhos, segundo a percepção dos pais, pode ser explicada justamente pela redução de cobranças por parte de figuras de autoridade nas relaçóes entre crianças que são vizinhas e que brincam e interagem mais livremente, na maioria das vezes à mercê de suas próprias regras. Aliado a isso, sem as restrições de espaço e/ou de recursos que a escola apresenta, brincar com os vizinhos, seja em suas casas, seja na rua, possibilita à criança com TDAH exercer sua criatividade, inventividade e propensão a brincadeiras que envolvam esforço físico, agitação e agilidade. Já com relação à diferença na amizade e proximidade relacional com os primos, dado que se destacou entre os dois grupos, pode-se apenas especular que o menino com TDAH seja preterido pelos membros da família extensa em virtude de seu comportamento tendenciosamente disruptivo e pela possibilidade de servir de modelo negativo às demais crianças da família.

Os dados com respeito à percepção dos pais sobre a razão pela qual o filho tem amizade próxima com outra criança se distribuíram de modo semelhante nos dois grupos. A única diferença mais saliente é com respeito à maior frequência de respostas de pais do grupo típico na categoria companheirismo/convivência. Também há uma questão a ser levantada para explicar este dado, mas sem intenção de com ela propor conclusóes. Possivelmente os pais dos meninos com TDAH não observam uma frequência notável de convivência entre seu filho e a criança apontada como amiga próxima. Isso poderia ser indicativo da dificuldade de crianças com TDAH de desenvolver amizades verdadeiramente próximas e duradouras, que requerem frequente convivência e companheirismo evidente. Todavia, estudos mais aprofundados com crianças brasileiras diagnosticadas com TDAH serão necessários para melhor embasar esta afirmação.

Quanto à forma de os pais lidarem com as amizades do filho, surpreende a diferença notada entre o grupo típico e o grupo clínico. Cinco vezes mais pais 
de crianças típicas assumiram restringir as amizades do filho na comparação com os pais de meninos com TDAH. Pais de crianças com transtornos de desenvolvimento são comumente vistos como superprotetores e extremamente envolvidos com o cotidiano de suas crianças. Bolsoni-Silva e del Prette (2002) e Bolsoni-Silva e Marturano (2007) argumentam nesta direção de uma maior atenção dos pais sobre a vida social dos filhos com problemas de conduta. No entanto, as restrições quanto às amizades se destacaram nos pais de crianças típicas e não com TDAH. Isso pode ser compreendido a partir da questáo de que pais de crianças com TDAH são orientadas por psicoterapeutas, psiquiatras e educadores a procurar fazer e manter amizades, como realmente foi apontado na fala de um dos pais participantes.

Três pais do grupo típico (que serão identificados pelas letras $\mathrm{G}, \mathrm{H}$ e O) acrescentaram um comentário ao final da entrevista. Segundo G, "acho que (meu filho) poderia ter mais amigos, mas tenho medo; a gente não sabe o que acontece nas amizades das crianças, cada pai é de um jeito, então não deixo muito não...”. Esta fala é ilustrativa da frequência encontrada no grupo de pais típicos que admitiram restringir as amizades do filho. Aproximando este dado à literatura sobre estilos parentais, poder-se-ia interpretar esta preocupação dos pais do grupo típico com o monitoramento das atividades desenvolvidas por seus filhos, inclusive na companhia de outras crianças. Estas outras crianças, por sua vez, e como mesmo sugerido na fala ora em análise, trazem consigo outras vivências de valores morais desenvolvidos em suas famílias e grupos culturais. A atenção dos pais quanto a estes aspectos morais é identificada por Sampaio e Gomide (2006) como comportamento moral, e a atenção às atividades é entendida como monitoria positiva - estratégias avaliadas nos estilos parentais.

$\mathrm{Na}$ visão de $\mathrm{H}$, “(meu filho) tem facilidade para fazer amizade”. Na percepçâo de $\mathrm{O}$, "sou hiperativa, acho que (meu filho) também é". Além destes dados, relata-se que o participante $\mathrm{J}$ optou por não responder à questão sobre como ele lida com as amizades do filho, justificando que "não tenho conhecimento profundo das amizades dele". Esta fala pode indicar uma posição mais alheia deste responsável com respeito às relaçóes de pares do filho. A respeito disso pode-se lembrar dos dados de Kunrath et al. (2006) acerca do cansaço emocional e consequente baixo monitoramento parental de pais de crianças com TDAH.

Dez pais de crianças com TDAH acrescentaram comentários espontâneos finais às suas entrevistas. $O$ responsável $G$ confidenciou que "(meu filho) não é de ter muitos amigos nem fica brincando muito tempo na rua, brinca e vem pra dentro". Já o responsável I afirmou que "(meu filho) é muito apegado aos amigos, a gente acha que ele se rebaixa porque é muito grudado". Mesmo se tratando de

Psic. Clin., Rio de Janeiro, vol. 25, N.I, P. 53-72, 2013 
duas crianças com TDAH, é digna de nota a diferença na percepção destes dois pais sobre as relaçóes de amizade do filho. Enquanto uma das crianças é vista como tendo poucos amigos, a outra é considerada quase como tendo amigos demais. Acredita-se que esta diferença de percepção dos pais possa estar atrelada ao conhecimento que estes possuem sobre a vida social de suas crianças. Como já referido, também pode ser em virtude de uma visão adultocêntrica de amizade.

A Tabela 3 apresenta dados comparativos entre meninos típicos e seus pais, sobre um mesmo conjunto de aspectos das amizades destas crianças: presença de um colega na vida da criança com quem ela gosta mais de estar junto, origem desse amigo, justificativa para serem amigos, atividades que compartilham e presença de amizades extras.

Tabela 3. Frequências de respostas de pais e de seus filhos do grupo típico sobre amizade

\begin{tabular}{|c|l|c|c|}
\hline Aspectos analisados & Categorias de respostas & $\begin{array}{c}\text { Pais } \\
\mathrm{f} \\
(\mathrm{n}=21)\end{array}$ & $\begin{array}{c}\text { Filhos } \\
\mathrm{f} \\
(\mathrm{n}=21)\end{array}$ \\
\hline \multicolumn{2}{|c|}{ Criança tem colega com quem gosta de estar } & 21 & 21 \\
\hline Origem do colega & primo & 09 & 02 \\
& colega escola & 08 & 16 \\
& vizinho & 03 & 01 \\
Justificativa da amizade & outra & 01 & 02 \\
\hline \multicolumn{2}{|c|}{ Amizades extras } & 08 & 05 \\
& companheirismo/ & 07 & 12 \\
& brincar & 01 & 01 \\
\hline \multicolumn{2}{|c|}{ atributos amigo } & 21 & 19 \\
\hline & brincar & 06 & 03 \\
\hline
\end{tabular}

$\mathrm{Na}$ Tabela 3 não constam dois grupos de respostas específicas de pais e de filhos sobre a justificativa da amizade. Apenas os pais perceberam as seguintes justificativas, com indicação da frequência: comportamentos pró-sociais (06), similaridades (06), familiaridades ou trocas (03), e reciprocidade (02). No caso dos filhos, os dados encontrados foram: ajudar (03), conversar (05), gostar (05) e outras respostas (05). Também apenas filhos indicaram conversar como uma atividade compartilhada com o amigo (03).

Psic. Clin., Rio de Janeiro, vol. 25, N.I, P. 53-72, 2013 
Em complemento aos dados da Tabela 3, foi calculada a porcentagem de concordância entre as respostas de pais e de seus filhos do grupo típico em outros aspectos da amizade investigados no estudo. Assim, enquanto houve $48 \%$ de concordância quanto à frequência de contato do filho com o amigo, encontraram-se $33 \%$ de concordância sobre a idade do amigo indicado e $24 \%$ sobre a duração da amizade.

O que os dados comparativos entre pais e seus filhos típicos mostram é, em suma, que os progenitores de crianças típicas realmente conhecem pouco sobre as amizades dos filhos. Muitos pais, por exemplo, acreditam que a amizade próxima do filho vem de relaçóes familiares, como no caso de primos. Todavia os meninos indicaram colegas de escola como amizades com as quais gostam de estar. Assim, a percepçáo dos pais pode estar altamente conectada aos encontros familiares nos quais podem acompanhar mais de perto as atividades dos filhos e suas interaçôes com os primos. Sem contato com as amizades dos filhos fora do âmbito familiar, estas não vêm à tona quando se solicita aos pais sobre a amizade próxima de seu filho. Outra questão que pode estar implicada nesta percepção parental sobre amizade é a hierarquia pressuposta, na cultura brasileira, das relações de parentesco sobre as de amizade. Realmente, há uma ideia compartilhada de que a família, a despeito da qualidade de suas relaçóes, é sempre preferida sobre as relaçóes de amizade em situaçốes de alta necessidade.

Quanto às justificativas para a amizade entre o filho e a criança indica$\mathrm{da}$, pais e filhos parecem concordar quanto ao companheirismo/convivência e ao brincar. Sáo aspectos muito indicados na literatura como fonte de relaçóes de amizade entre crianças (Bukowski et al., 1996). No entanto, as demais percepçóes tanto de pais como de filhos diferenciaram um tanto em algumas especificidades: enquanto os pais tendem a justificar a amizade infantil também com similaridades e comportamentos pró-sociais, as crianças tendem a citar também a questão do apreço pelo amigo (gostar) e o conversar. Estas duas questôes são básicas nas amizades infantis, ao lado das similaridades. Já a indicação dos comportamentos pró-sociais pode estar ligada a uma maior preocupação dos pais em que suas crianças desenvolvam habilidades sociais quando interagem com outras crianças, como referido por Sampaio e Gomide (2006) na questão do comportamento moral nos estilos parentais. Assim, os progenitores podem estar mais atentos a estes aspectos quando observam seus filhos na companhia de amigos.

Embora não seja um dado muito semelhante àquele detectado no grupo dos meninos, grande parte dos pais percebe que seus filhos possuem amizades extras em suas vidas. Ainda assim, pouco concordam com os filhos no que diz respeito à identidade da amizade mais próxima da criança. Esta conclusão pode ser

Psic. Clin., Rio de Janeiro, vol. 25, N.I, P. 53-72, 2013 
traçada também a partir da leitura das porcentagens sobre a baixa porcentagem de concordância entre pais e filhos típicos sobre dados complementares sobre as amizades destes (idade, frequência de contato e duração). Realmente, as amizades das crianças ainda não parece ser prioridade no conjunto de aspectos sob atenção parental no cuidado e educação dos filhos.

$\mathrm{Na}$ Tabela 4 há dados comparativos entre meninos do grupo clínico e seus pais sobre o mesmo conjunto de aspectos das amizades destas crianças analisado para o grupo típico. São as questóes de presença de um colega na vida da criança com quem ela gosta mais de estar junto, origem desse amigo, justificativa para serem amigos, atividades que compartilham e presença de amizades extras.

Tabela 4. Frequências de respostas de pais e de seus filhos do grupo clínico sobre amizade

\begin{tabular}{|c|c|c|c|}
\hline Aspectos analisados & Categorias de respostas & $\begin{array}{c}\text { Pais } \\
\mathrm{f} \\
(\mathrm{n}=15)\end{array}$ & $\begin{array}{c}\text { Filhos } \\
\mathrm{f} \\
(\mathrm{n}=18)\end{array}$ \\
\hline \multicolumn{2}{|c|}{ Criança tem colega com quem gosta de estar } & 15 & 18 \\
\hline Origem do colega & primo & 02 & 01 \\
& colega escola & 04 & 13 \\
& vizinho & 08 & - \\
Justificativa da amizade & outra & 01 & 04 \\
\hline & companheirismo & 03 & 01 \\
& ou convivência & 06 & 14 \\
& brincar & 01 & 02 \\
& familiaridade ou trocas & 03 & 04 \\
& atributos amigo & & 15 \\
\hline \multirow{2}{*}{ Atividades compartilhadas } & brincar & 14 & 05 \\
& outras & 02 & 02 \\
\hline \multicolumn{2}{|r|}{ Amizades extras } & - & 14 \\
\hline
\end{tabular}

$\mathrm{Na}$ Tabela 4 não constam os dados de justificativas apontadas ou somente por pais ou somente por filhos. No grupo dos pais, as categorias de respostas encontradas foram (com a frequência indicada): comportamentos pró-sociais (04), similaridades (04) e reciprocidade (03). No caso dos filhos, os resultados foram: ajudar (03), gostar (01) e outras respostas (03). Também foi obtida a porcentagem de concordância entre pais e filhos do grupo clínico sobre a idade do amigo, 
a frequência de contato e a duração deste relacionamento. Para estas variáveis, foram observados 33\%, 27\% e 27\% de concordância, respectivamente.

À primeira vista já se nota que todos os meninos deste grupo clínico indicaram uma amizade em suas vidas, mas três pais do grupo negaram esta informação. Duas hipóteses-explicativas podem ser consideradas diante deste dado. De um lado, poder-se-ia apontar, mais uma vez, a falta de conhecimento da vida social do filho fora do âmbito familiar e da companhia de primos. De outro, há pesquisas que indicam que, como a percepção das crianças com TDAH está alterada, ela tende a náo reconhecer dificuldades na relação com pares. Assim, estas crianças poderiam não ter uma amizade próxima, mas entendem o contrário. Segundo Hoza, Waschbusch, Pelham, Molina e Milich (2000), isso pode ser devido ao viés positivo que crianças com TDAH costumam apresentar. De toda forma, ambas hipóteses encontram respaldo em dados e mais pesquisas brasileiras auxiliarão nesse sentido.

Há um desequilíbrio quanto à origem da amizade. Enquanto os pais de meninos com TDAH creem que o filho tem amizade próxima com um vizinho, a criança indica o colega de escola. É possível que estes pais tenham mais contato com a vida social dos filhos quando na companhia de vizinhos e à mercê de monitoramento mais atento. A vida escolar, portanto, seria melhor observada pelos professores, incluindo aí as relaçóes sociais das crianças.

$\mathrm{Na}$ justificativa para a amizade, à semelhança dos pais e seus filhos do grupo típico, o brincar foi o argumento mais citado pelas crianças. Os pais distribuíram suas respostas em aspectos como comportamentos pró-sociais, similaridades, atributos do amigo e reciprocidade. Ao menos quanto aos atos pró-sociais e aos atributos específicos que o amigo possui que o caracteriza como tal (p. ex., ele é legal, tem paciência), como discutido, são aspectos de maior interesse na visão dos pais quando estes se dedicam a acompanhar de perto as amizades de seus filhos, especialmente no contexto de problemas de comportamento.

Interessantemente, nem os meninos do grupo típico, nem os do grupo clínico indicaram a reciprocidade como algo a justificar uma relação de amizade. Muito provavelmente isto ocorreu porque não foi direcionada à criança uma pergunta específica sobre esta questão. Em outras oportunidades foi possível observar indícios de reciprocidade, como troca de brinquedos, favores ou convites e outras manifestaçôes de retribuição.

Ficaram bastante equilibradas entre pais e filhos do grupo clínico a indicação do brincar como atividade compartilhada entre o filho e sua amizade próxima. Este mesmo resultado foi observado no grupo típico na comparação com seus pais. Além disso, ambos os grupos de crianças, embora em frequência

Psic. Clin., Rio de Janeiro, vol. 25, N.I, P. 53-72, 2013 
reduzida, mencionaram a atividade de conversar com o amigo como algo com ele compartilhado. Dada a idade das crianças, este tipo de resposta é esperado, dada como reflexo de sua cognição, dedicada aos eventos mais aparentes das relaçóes interpessoais, como conversar (por exemplo, estágio operatório concreto; Piaget, 1964/1973).

Os dados sobre amizades extras, comparados aos do grupo clínico, mostraram diferenças aproximadas entre pais e filhos. Os meninos apresentaram uma frequência um pouco maior que seus pais no que diz respeito à presença de amizades extras em suas vidas. Todavia a diferença entre pais e filhos foi maior no grupo clínico, podendo, mais uma vez, indicar tanto o desconhecimento dos pais sobre os amigos dos filhos, quanto a interferência de um viés positivo nos julgamentos de crianças com TDAH.

Já as porcentagens de concordância entre pais e filhos do grupo clínico foram menores do que as do grupo típico nos aspectos idade do amigo e frequência de contato com ele. Ao menos a metade dos pais e seus filhos típicos concordaram com a idade do amigo, enquanto este dado náo passou de um terço no grupo clínico. A concordância sobre a duraçáo da amizade foi semelhante nos dois grupos, embora levemente menor no grupo típico.

Partindo-se da literatura de cuidado e educação das crianças por parte de seus pais, argumentou-se sobre a pequena atençáo dada por eles às amizades dos filhos. A literatura sobre estilos parentais prevê a necessidade de atenção à vida social dos filhos. Todavia pais de crianças com problemas de comportamento são mais orientados a atentar para as relaçóes sociais dos filhos, como nos casos de TDAH. Estudos com estas crianças, dedicados a promover relaçóes de amizade, têm mostrado bons resultados nessa direção, especialmente quando os pais estão envolvidos na intervenção. $\mathrm{O}$ presente trabalho procurou examinar mais atentamente dados inéditos sobre presença de um bom amigo, idade, frequência de contato, duração da amizade, origem, justificativa, atividades compartilhadas, reciprocidade e presença de amizades extras. Estes dados foram comparados entre pais e filhos, divididos em grupo clínico (menino diagnosticado com TDAH) e grupo típico (sem TDAH). Foram comparadas também as estratégias que os pais utilizam para lidar com as amizades de seus filhos.

Os resultados encontrados têm a intençáo de motivar novos estudos que examinem, mais intensa e extensamente, tanto a amizade em crianças com TDAH como o envolvimento dos pais na vida social dos filhos. Duas hipóteses-explicativas guiaram a interpretação dos resultados: pais alheios às relaçóes sociais dos filhos, $\mathrm{e}$ crianças com TDAH com um viés positivo acerca de suas amizades. Aliado a isso, ponderou-se sobre uma tendência dos pais de compreender a amizade desde uma 
visão adultocêntrica. Quanto às limitaçôes do trabalho, o rapport com os pais do grupo típico pode ter sido influenciado pelo contato impessoal via telefone, o que pode ter inibido a expressão de detalhes sobre amizades do filho. Todavia, estes entrevistados forneceram tantos dados importantes quanto os pais do grupo clínico.

$\mathrm{O}$ TDAH é um dos transtornos mais estudados atualmente em crianças brasileiras. A literatura é frutífera e dedicada tanto às questôes de saúde como de educação destas crianças. A amizade é sabidamente promotora de desenvolvimento, de aprendizagem e de saúde. Também é reconhecido o papel dos pais na vida social de suas crianças. São dois aspectos que merecem maior atenção em termos de investimento científico, tanto com crianças sem transtornos como em crianças portadoras destes desafios. Resultados de tais investimentos podem fornecer subsídios tanto para a clínica infantil (a exemplo da postura de prática baseada em evidências) como para o melhor cuidado e educação das crianças.

\section{Referências}

Albertassi, I. \& Garcia, A. (2006). Crianças com necessidades especiais e seus amigos: um estudo na cidade de Vitória (ES). In: Garcia, A. (org.). Relacionamento interpessoal: estudos e pesquisas (pp. 55-73). Vitória: UFES/NIERI.

Bardin, L. (2009). Análise de conteúdo. São Paulo: Ediçóes 70.

Barkley, R. (2002). Transtorno do Déficit de Atenção/Hiperatividade - Guia completo para pais, professores e profissionais de saúde. Porto Alegre: Artmed.

Bellé, A., Andreazza, A., Ruschel, J. \& Bosa, C. (2009). Estresse e adaptaçấo psicossocial em mães de crianças com transtorno de déficit de atenção/hiperatividade. Psicologia: Reflexão e Crítica, 22(3), 317-325.

Bolsoni-Silva, A. \& Del Prette, A. (2002). O que os pais falam sobre suas habilidades sociais e de seus filhos? Argumento, 3(7), 71-86.

Bolsoni-Silva, A. \& Marturano, E. (2007). A qualidade da interação positiva e da consistência parental na sua relação com problemas de comportamentos de pré-escolares. Revista Interamericana de Psicologia, 41(3), 349-358.

Brito, G. (2006). Escala de Avaliação do Comportamento Infantil para o professor. São Paulo: Vetor.

Bukowski, W., Newcomb, A. \& Hartup, W. (1996). Friendship and its significance in childhood and adolescence: introduction and comment. In: Bukowski, W., Newcomb, A. \& Hartup, W. (orgs.). The company they keep (p. 1-15). Cambridge: University Press.

Daly, B., Creed, T., Xanthopoulos, M. \& Brown, R. (2007). Psychosocial treatments for children with attention deficit/hyperactivity disorder. Neuropsychology Review, 17, 73-89.

Psic. Clin., Rio de Janeiro, vol. 25, N.I, P. 53-72, 2013 


\section{Pais, filhos, amizades e TDAH $\bullet 71$}

Garcia-Serpa, F., Del Prette, Z. \& Del Prette, A. (2006). Meninos pré-escolares empáticos e não-empáticos: empatia e procedimentos educativos dos pais. Revista Interamericana de Psicologia, 40(1), 77-88.

Goldstein, S. \& Goldstein, M. (2002). Seriam os amigos um sonho impossível para a criança hiperativa? In: Goldstein, S. \& Goldstein, M. Hiperatividade: como desenvolver a capacidade de atenção da criança (pp. 81-104). Campinas: Papirus.

Hoza, B., Mrug, S., Gerdes, A. C., Hinshaw, S. P., Bukowski, W. M., Gold, J. A., Kraemer, H. C., Pelham Jr, W., Wigal, T. \& Arnold, L. E. (2005). What aspects of peer relationships are impaired in children with attention/deficit hyperactivity disorder? Journal of Consulting and Clinical Psychology, 73(3), 411-23.

Hoza, B., Mrug, S., Pelham Jr., W., Greiner, A. \& Gnagy, E. (2003). A friendship intervention for children with attention-deficit/hyperactivity disorder: preliminary findings. Journal of Attention Disorders, 6(3), 87-96.

Hoza, B., Waschbusch, D., Pelham, W., Molina, B. \& Milich, R. (2000). Attention-deficit hyperactivity disordered and controlled boys' responses to social success and failure. Child Development, 71(2), 432-446.

Kunrath, L., Wagner, A. \& de Jou, G. (2006). A educação dos filhos com transtorno de déficit de atenção e hiperatividade: o que fazer? Psicologia em Revista, 12(20), 235-250.

Macarini, S., Martins, G., Minetto, M. \& Vieira, M. (2010). Práticas parentais: uma revisão da literatura brasileira. Arquivos Brasileiros de Psicologia, 62(1), 119-134.

Pelham Jr., W. \& Bender, M. E. (1982). Peer relationships in hyperactivity children: description and treatment. Advances in learning and behavioral disabilities, 1, 366-436.

Phelan, T. W. (2005). TDA/TDAH: Transtorno de Déficit de Atenção e Hiperatividade. São Paulo: M. Books.

Piaget, J. (1973). Seis estudos de psicologia. Rio de Janeiro: Forense. (Trabalho original publicado em 1964).

Sampaio, I. T. \& Gomide, P. I. (2006). Inventário de Estilos Parentais (IEP) - Gomide (2006) Percurso de Padronização e Normatização. Psicologia Argumento, 25(48), 15-26.

Selman, R. (1980). The growth of interpersonal understanding. New York: Academic.

Selman, R. (1981). The child as a friendship philosopher. In: Asher, S. \& Gottman, J. (orgs.). The development of children friendships (pp. 242-272). Cambridge: University Press.

Sena, S. S. (2009). Relaçôes de amizade em meninos com TDAH. (Dissertação de Mestrado. Programa de Pós-Graduação em Psicologia da Universidade Federal de Minas Gerais, Belo Horizonte, MG).

Sena, S. S. \& Souza, L. K. (2008). Desafios teóricos e metodológicos na pesquisa psicológica sobre TDAH. Temas em Psicologia, 16(2), 243-259.

Sena, S. S. \& Souza, L. K. (2010). Amizade, infância e TDAH. Contextos Clínicos, 3(1), 18-28.

Psic. Clin., Rio de Janeiro, vol. 25, N.I, P. $53-72,2013$ 
72 - Pais, filhos, amizades e TDAH

\section{Nota}

${ }^{1}$ Este estudo é parte da Dissertação de Mestrado defendida pela primeira autora sob orientação da segunda no PPG-Psicologia da UFMG. Os dados aqui analisados compóem o último conjunto de dados inéditos do trabalho. Agradecimentos: V. Haase, L. Magalhães, T. Carvalho, S. Peron, crianças, familiares, profissionais, professores e escolas que colaboraram com esta pesquisa.

Recebido em 07 de julho de 2012

Aceito para publicaçáo em 15 de janeiro de 2013

Psic. Clin., Rio de Janeiro, vol. 25, N.I, P. 53-72, 2013 